\title{
SUBSTITUIÇÃO DE PROTEÍNAS DA CARNE POR PROTEÍNAS DO CONCENTRADO PROTÉICO DE SORO E ADIÇÃO DE $\mathrm{CaCl}_{2} \mathrm{EM}$ SISTEMA CÁRNEO
}

\author{
MÁRCIA DE MELLO LUVIELMO* \\ ALOÍSIO JOSÉ ANTUNES**
}

\begin{abstract}
O presente trabalho teve por objetivo avaliar a substituição de proteínas da carne por concentrados protéicos de soro (CPS) e a adição de $\mathrm{CaCl}_{2}$ em sistema cárneo. O estudo mostrou que o CPS 80 e o CPS 8002 podem constituir alternativa viável para os "batters" cárneos, obtendo-se produtos com atributos de textura muito similares ao padrão sem substituição. Nas condições estudadas, a adição do $\mathrm{CaCl}_{2}$ não melhorou as propriedades reológicas do sistema cárneo.
\end{abstract}

PALAVRAS-CHAVE: SORO; SAIS; CÁLCIO; SALSICHA; PROTEÍNA; SISTEMA CÁRNEO.

\section{INTRODUÇÃO}

Os sistemas cárneos cominuídos, algumas vezes chamados de emulsões cárneas, não constituem emulsão verdadeira e devem ser denominados de misturas cárneas ou "batters" cárneos (ZIEGLER e ACTION, 1984). "Batter" cárneo pode ser descrito como a mistura finamente fragmentada de proteínas musculares, partículas de gordura, água, sal e outros aditivos que resultam em massa homogênea após desnaturação térmica das proteínas. Os "batters" cárneos fazem parte da dieta do brasileiro e apresentam grande importância econômica, sendo servidos domesticamente, em restaurantes ou em cozinhas industriais (GORDON e BARBUT, 1992; COSENZA et al., 2003).

Engenheira de Alimentos, Mestre em Nutrição Aplicada a Tecnologia de Alimentos, Laboratório de Funcionalidade de Proteínas, Faculdade de Engenharia de Alimentos, Universidade Estadual de Campinas, Campinas, SP, Brasil (e-mail: luvielmo@fea.unicamp.br)

Centro de Pesquisa em Ciência e Tecnologia do Leite, Fazenda Experimental de Tamarana, Universidade Norte do Paraná, Tamarana, PR, Brasil. 
A gelatinização das proteínas do "batter" cárneo pode ser manipulada para produzir estrutura capaz de ligar água e, conseqüentemente, apresentar boa textura. Para isso, é preciso controlar rigorosamente o pH, a força iônica, a temperatura do ponto final de trituração e o processamento (GORDON e BARBUT, 1992).

As proteínas miofilibrilares constituem 50 a $55 \%$ do total de proteínas do músculo, sendo a miosina (50-55\%) e a actina (20-25\%) as proteínas majoritárias e as principais responsáveis pelas propriedades funcionais dos produtos cárneos processados (SMITH, 1988).

O produto suculento resulta de sistema com grande capacidade de reter água. Outras características da carne estão relacionadas com a capacidade de retenção de água (CRA) como a maciez, a cor e o gosto. Existe interesse econômico e prático na CRA em função da sua importância para o transporte, estocagem, enlatamento, congelamento e descongelamento de produtos cárneos (CORREIA e MITTAL, 2000; HAMM, 1960).

A capacidade das proteínas do soro em formar géis estáveis, sob aquecimento em temperaturas de $70^{\circ} \mathrm{C}$ a $90^{\circ} \mathrm{C}$, constitui importante propriedade funcional para a manufatura de produtos cárneos, de padaria, texturizados e produtos lácteos (DE WIT, 1989). Os géis são estruturas capazes de imobilizar grandes quantidades de água e outros componentes alimentícios (KUHN e FOEGEDING, 1991b). O processo de gelatinização tem sido descrito em detalhes por vários autores, entre os quais MORR e HA (1993); MULVIHILL e KINSELLA (1987); KILARA (1994).

As propriedades do concentrado protéicos de soro (CPS) em produtos cárneos são altamente variáveis. A influência de fatores intrínsecos e extrínsecos nas propriedades funcionais do CPS em sistemas cárneos deve ser definida e tais fatores caracterizados para que se possa expandir o uso dessas proteínas na indústria cárnea (CORREIA e MITTAL, 2000; SMITH e ROSE, 1995).

COSENZA et al. (2003) desenvolveram salsicha defumada de carne de cabra, ressaltando a importância de testar os extensores de carne (como o CPS) a fim de reduzir o custo desses produtos que apresentam alto valor agregado em função de seu apelo exótico.

Em termos nutricionais as proteínas do soro são excelentes fontes 
de aminoácidos essenciais, particularmente lisina. $O$ alto conteúdo de lisina pode ser benéfico pela reposição da lisina perdida durante 0 processo de cocção em carnes processadas (LEE, CANNON e HUFFMAN, 1980).

ENSOR et al. (1987) compararam o efeito dos mesmos níveis de CPS com isolado protéico de soja e leite seco desengordurado reduzido de cálcio em produtos cárneos do tipo emulsão. Verificaram a viabilidade de seu uso como ligante alternativo para melhorar a estabilidade, a textura e os atributos sensoriais dos referidos produtos.

RAO et al. (1999) mostraram que a adição de 1,5\% de CPS em salsichas de frango defumada melhora a estabilidade da emulsão, o $\mathrm{pH}$ da mistura e o rendimento final do produto.

EL-MAGOLI, LAROIA e HANSEN (1996) avaliaram as características de cocção de empanados de carne bovina com baixo teor de gordura (10 - 11\% de gordura), formulados com 1 a $4 \%$ de CPS. O produto com $4 \%$ de CPS obteve o maior rendimento e o menor percentual de retenção.

Vários estudos evidenciaram que os sais neutros exerciam efeito interessante na hidratação das proteínas. A adição de $\mathrm{NaCl}$ em proteínas aumenta fortemente a CRA (HAMM, 1960). O efeito do $\mathrm{NaCl}$ na capacidade de retenção de água depende do $\mathrm{pH}$ do tecido. $\mathrm{O} \mathrm{NaCl}$ aumenta a CRA das proteínas em $\mathrm{pH}>$ ponto isoelétrico (IP) e diminui em $\mathrm{pH}<\mathrm{IP}$. Esse efeito deve-se, predominantemente, ao íon cloreto $(\mathrm{Cl})$ do $\mathrm{NaCl}$ que causa enfraquecimento da interação entre grupos carregados opostamente em pH > IP (HAMM, 1974).

A CRA é mínima em pH 5,0 que corresponde ao ponto isoelétrico da actomiosina, a proteína que constitui a estrutura do músculo protéico (HAMM, 1974).

Os íons bivalentes, tais como cálcio, podem formar pontes iônicas entre grupos carboxílicos adjacentes. Ainda que altas concentrações de sódio estejam presentes é possível que a $65^{\circ} \mathrm{C}$ as proteínas solúveis estejam também fortemente ligadas por íons bivalentes, tais como 0 cálcio (SMITH e ROSE, 1994).

WIERBICKI, CAHILL e DEATHERAGE (1957) estudaram o efeito da adição dos cloretos de sódio $(\mathrm{NaCl})$, potássio $(\mathrm{KCl})$, cálcio $\left(\mathrm{CaCl}_{2}\right)$ e 
magnésio $\left(\mathrm{MgCl}_{2}\right)$ em carnes. A CRA das proteínas cárneas aumentou nos experimentos em que os cloretos de sódio, potássio, cálcio e magnésio foram adicionados à carne antes do aquecimento $\left(70^{\circ} \mathrm{C}\right)$, exceto para concentrações muito altas dos sais adicionados. A umidade espremível da carne cozida mostrou-se menor para os tratamentos com $\mathrm{CaCl}_{2}$ e $\mathrm{MgCl}_{2}$ do que para os com $\mathrm{NaCl}$ e KCl. Tal fato demonstra que os cátions bivalentes diminuem o encolhimento em maior grau do que os cátions monovalentes. A combinação desses cloretos evidenciou que a combinação de $\mathrm{NaCl}$ e $\mathrm{MgCl}_{2}$ promove aumento na CRA em carnes cozidas.

Em função de estudos anteriores, o presente trabalho teve por objetivo avaliar a substituição de proteínas da carne de frango por CPS e verificar o efeito da adição de $\mathrm{CaCl}_{2}$ em sistema cárneo.

\section{MATERIAL E MÉTODOS}

\subsection{MATÉRIA-PRIMA}

A matéria-prima constituiu-se de carne de peito de frango desossada (manualmente), sem pele, obtida da Cooperativa Agropecuária HOLAMBRA. Após o abate, essa carne foi congelada rapidamente a $-18^{\circ} \mathrm{C}$ em sacos de $1,5 \mathrm{~kg}$ e transferida para refrigerador $\left(4^{\circ} \mathrm{C}\right)$ 15 horas antes de ser processada.

O toucinho, removido da porção costo lombar de suínos, foi obtido de mercado de Campinas, congelado rapidamente a $-18^{\circ} \mathrm{C}$ em sacos de $500 \mathrm{~g}$ e transferido do congelador para refrigerador $\left(4^{\circ} \mathrm{C}\right)$ uma hora antes de ser triturado.

Os ingredientes comerciais constituíram-se de sal ( $\mathrm{NaCl})$, tripolifosfato de sódio (NaTPP), nitrito de sódio, ascorbato de sódio, concentrado protéico de soro de leite de bovino (CPS80 e CPS8002), cloreto de cálcio $\left(\mathrm{CaCl}_{2}\right)$ e condimentos (condimento pronto, pimenta, noz moscada e orégano). As salsichas foram embutidas em tripas artificiais de celulose com calibre de $22 \mathrm{~mm}$.

\subsection{PROCESSAMENTO}

Nas Figuras 1 e 2 constam os fluxogramas de processamento das salsichas e o de cocção das salsichas, respectivamente. 


\section{FIGURA 1 - FLUXOGRAMA DE PROCESSAMENTO DAS SALSICHAS}

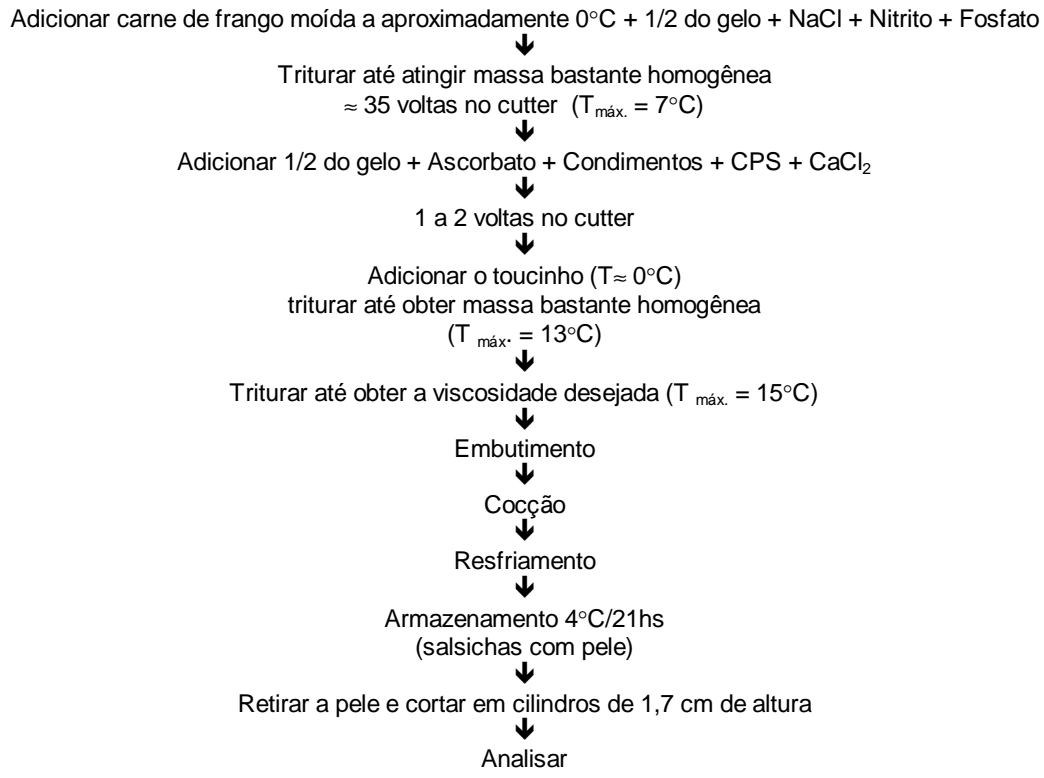

FIGURA 2 - FLUXOGRAMA DE COCÇÃO DAS SALSICHAS

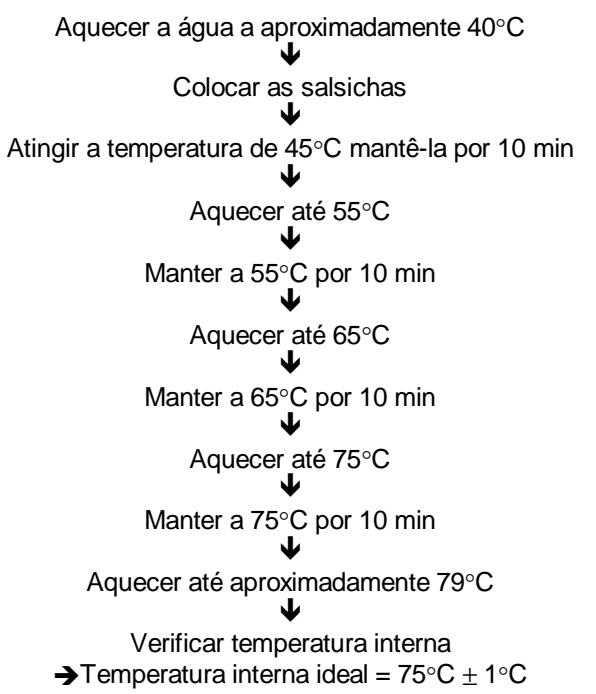




\subsection{COMPOSIÇÃO DAS FORMULAÇÕES}

As formulações com $7 \%$ e $8 \%$ de CPS foram processadas com o CPS80 e CPS8002, considerando para o cálculo seu percentual de proteínas (Quadro 1).

As formulações com 7 e $8 \%$ de CPS foram processadas com e sem a adição de 7,5; 15,0; 30,0 e 75,0 mM de $\mathrm{CaCl}_{2}$ (correspondente a 0,015\%, 0,03\%, 0,06\% e 0,15\% da formulação).

\section{QUADRO 1 - COMPOSIÇÃO DAS FORMULAÇÕES}

\begin{tabular}{|l|c|c|c|}
\hline \multirow{2}{*}{ Matéria-prima } & \multicolumn{3}{|c|}{ Quantidade g/\% } \\
\cline { 2 - 4 } & Formulação Padrão & $\begin{array}{c}\text { Formulação com } \\
\mathbf{8} \% \text { CPS }\end{array}$ & $\begin{array}{c}\text { Formulação com } \\
\mathbf{7} \% \text { de CPS }\end{array}$ \\
\hline Peito de Frango & $1200,0 / 60,0$ & 1104,0 & 1116,0 \\
\hline CPS-80 & 0,0 & $26,10 / 8,0$ & $22,84 / 7,0$ \\
\hline Toucinho & $360,0 / 18,0$ & $360,0 / 18,0$ & $360,0 / 18,0$ \\
\hline Sal & $44,0 / 2,2$ & $44,0 / 2,2$ & $44,0 / 2,2$ \\
\hline Fosfato & $6,0 / 0,3$ & $6,0 / 0,3$ & $6,0 / 0,3$ \\
\hline Agua & $382,0 / 19,08$ & $382,0 / 19,08$ & $382,0 / 19,08$ \\
\hline Nitrito & $0,4 / 0,02$ & $0,4 / 0,02$ & $0,4 / 0,02$ \\
\hline Ascorbato & $1,0 / 0,05$ & $1,0 / 0,05$ & $1,0 / 0,05$ \\
\hline Condimentos & $6,4 / 0,32$ & $6,4 / 0,32$ & $6,4 / 0,32$ \\
\hline Agua Total & $1327,14 / 66,36$ & $1256,21 / 62,81$ & $1265,08 / 63,25$ \\
\hline
\end{tabular}

Relação Umidade/Proteína $=5,31$

\subsection{COMPOSIÇÃO QUÍMICA}

As determinações de proteína, umidade e cinzas das salsichas, dos CPS, da carne e do toucinho foram realizadas de acordo com a AOAC (1995), métodos 16193, 16192 e 16196, respectivamente.

A gordura do CPS foi determinada pelo Método de Roese-Gottlieb ( $\left.\mathrm{n}^{\circ} 16059\right)$ da AOAC (1995) e os lipídios totais para a carne e toucinho pelo método de Brigh e Dyer da AOAC (1995).

\subsection{ANÁLISES PARA AVALIAÇÃO DAS SALSICHAS}

\subsubsection{Umidade Espremível}

Determinou-se a \% de Umidade Espremível pelo método de 
JAUREGUI, REGENSTEIN e BAKER (1981) modificado. De cada 8 salsichas inicialmente escolhidas foi retirada uma amostra com $1,0 \mathrm{~g} \pm 0,2 \mathrm{~g}$, pesada em papel Whatman $\mathrm{n}^{\circ} 02$ e centrifugada a $16000 \mathrm{rpm} / 15 \mathrm{~min}$ a $6^{\circ} \mathrm{C}$.

\subsubsection{Avaliação de Cor}

Realizou-se a avaliação de cor pelos parâmetros L, a e b, utilizandose Colorímetro Minolta modelo CR200b.

\subsubsection{Medida das propriedades reológicas}

Mediram-se as propriedades reológicas de dureza, coesividade, elasticidade e mastigabilidade das amostras em texturômetro TA-XT2.

As condições utilizadas para o teste incluíram probe cilíndrico de acrílico com diâmetro de $20 \mathrm{~mm}$, velocidade do teste de $3 \mathrm{~mm} / \mathrm{s}$, sendo cada segmento comprimido a $50 \%$ da altura original com força de $20 \mathrm{~g}(0,2 \mathrm{~N})$, usando-se duas compressões.

\subsection{ANÁLISE ESTATIISTICA}

Os resultados encontrados foram avaliados estatisticamente pela média dos tratamentos, análise de variância e teste de Tukey (ao nível de significância de $5 \%$ - $p<0,05$ ) pelo programa estatístico SAS (1985.).

\section{RESULTADOS E DISCUSSÃO}

\subsection{COMPOSIÇÃO QUÍMICA DOS CONCENTRADOS PROTÉICOS DE SORO CPS80 E CPS8002}

A composição química dos concentrados protéicos de soro está apresentada nas Figuras 3 e 4, sendo o percentual de lactose calculado por diferença. 
FIGURA 3 - COMPOSIÇÃO DO CPS80

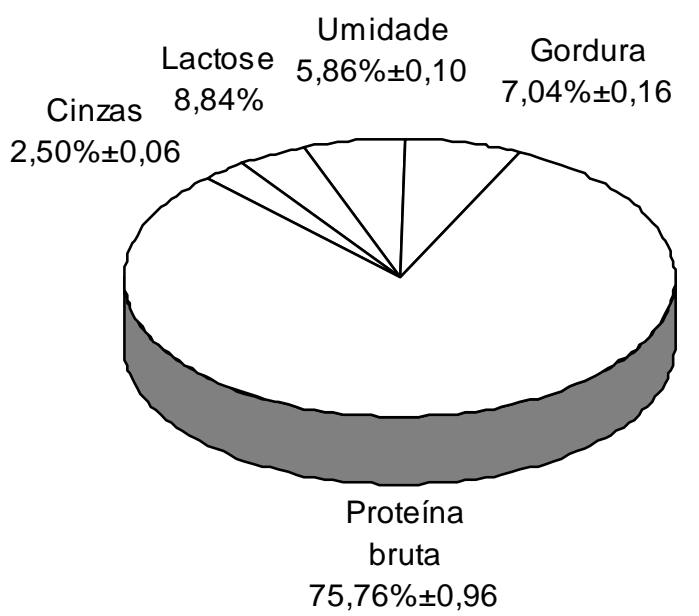

FIGURA 4 - COMPOSIÇÃO DO CPS8002

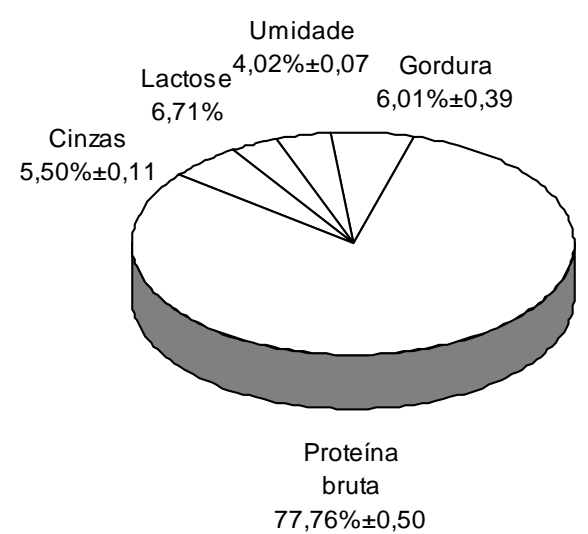

3.2 UMIDADE E PROTEÍNA DAS FORMULAÇÕES DE SALSICHA

Os teores de umidade e proteína das formulações de salsicha são apresentados no Quadro 2. 


\section{QUADRO 2 - TEORES DE UMIDADE E PROTEÍNA DAS FORMULAÇÕES DE SALSICHA}

\begin{tabular}{|c|c|c|}
\hline Formulação & $\%$ umidade & \% proteína \\
\hline Padrão & $62.15 \pm 0.91$ & $17.94 \pm 0.10$ \\
\hline $7 \%$ CPS 80 & $66.21 \pm 0.84$ & $17.53 \pm 0.16$ \\
\hline $8 \%$ CPS 80 & $64.28 \pm 0.97$ & $16.79 \pm 0.29$ \\
\hline $7 \%$ CPS $80+7.5$ & $66.24 \pm 0.22$ & $17.94 \pm 0.36$ \\
\hline $8 \%$ CPS $80+7.5$ & $65.55 \pm 0.90$ & $16.97 \pm 0.22$ \\
\hline $7 \%$ CPS $80+15$ & $64.85 \pm 0.65$ & $16.94 \pm 0.14$ \\
\hline $8 \%$ CPS $80+15$ & $65.48 \pm 0.59$ & $16.67 \pm 0.31$ \\
\hline $7 \%$ CPS $80+30$ & $65.86 \pm 0.14$ & $16.35 \pm 0.52$ \\
\hline $8 \%$ CPS $80+30$ & $66.01 \pm 0.54$ & $17.22 \pm 0.01$ \\
\hline $7 \%$ CPS $80+75$ & $65.11 \pm 0.51$ & $17.65 \pm 0.23$ \\
\hline $8 \%$ CPS $80+75$ & $64.38 \pm 0.47$ & $17.82 \pm 0.12$ \\
\hline $7 \%$ CPS 8002 & $65.88 \pm 0.35$ & $16.40 \pm 0.43$ \\
\hline $8 \%$ CPS 8002 & $64.88 \pm 0.61$ & $16.98 \pm 0.16$ \\
\hline
\end{tabular}

A formulação com CPS 8002 apresentou umidade espremível mais baixa que as demais e portanto maior suculência, mesmo não havendo diferença significativa $(p<0,05)$ em relação ao padrão (Figuras 5 e 6).

FIGURA 5 - PERCENTUAL DE UMIDADE ESPREMÍVEL PARA A FORMULAÇÃO PADRÃO E PARA AS FORMULAÇÕES COM 7\% DE CPS

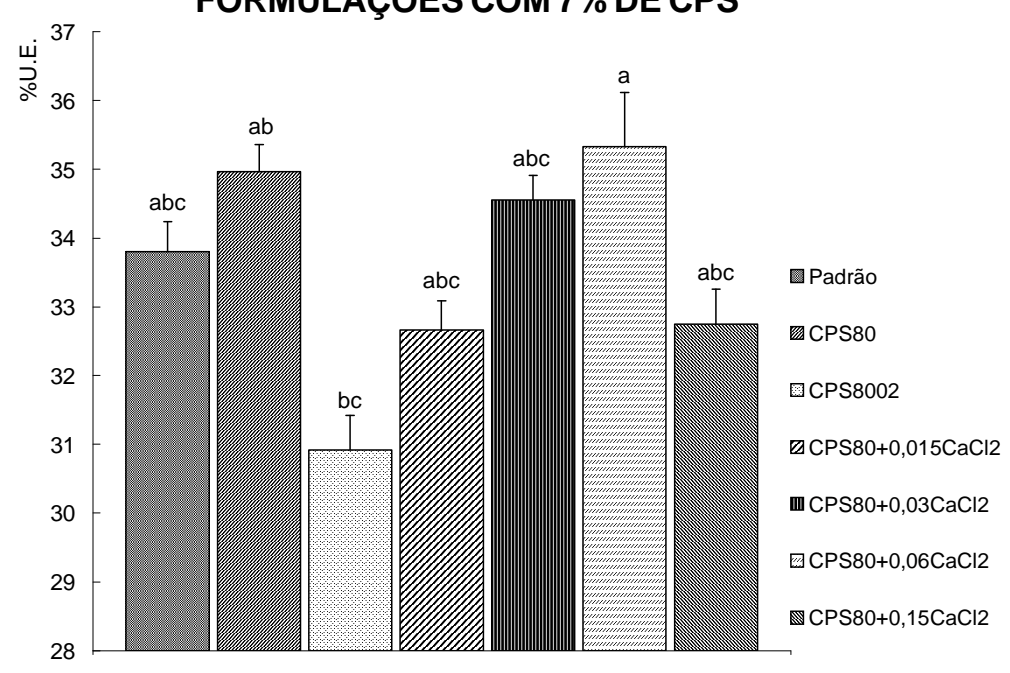




\section{FIGURA 6 - PERCENTUAL DE UMIDADE ESPREMÍVEL PARA A FORMULAÇÃO PADRÃO E PARA AS FORMULAÇÕES COM $8 \%$ DE CPS}

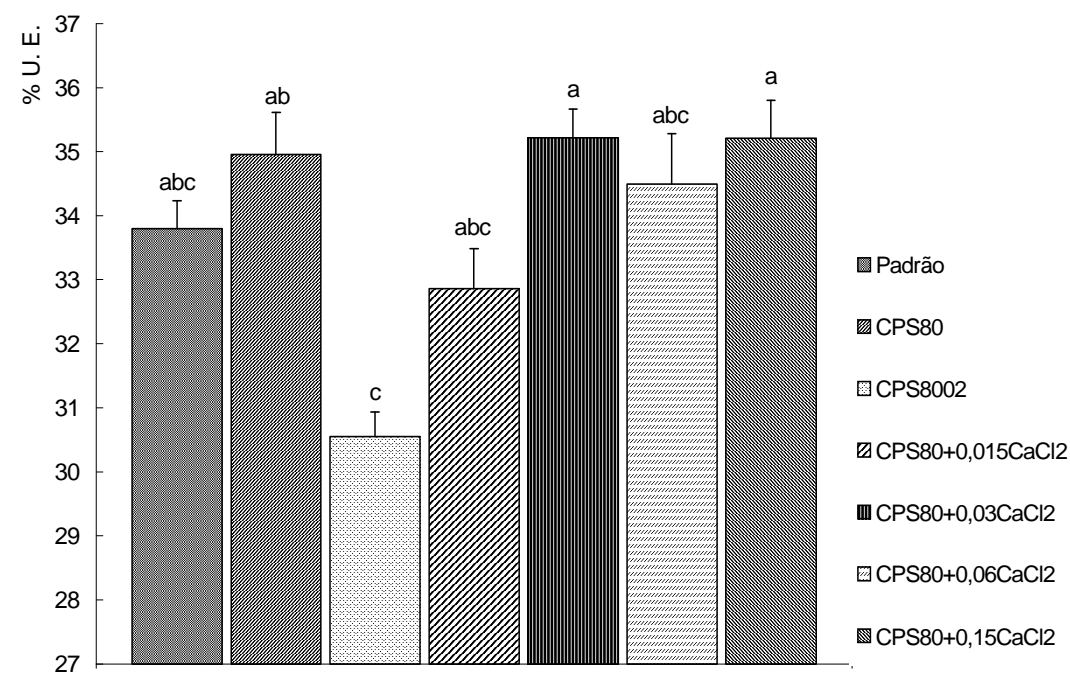

No estudo de RAO (1999), o conteúdo de umidade e de proteínas das salsichas com 1,5\% de CPS mostrou-se maior que o conteúdo de umidade e proteínas da formulação padrão. Verificou-se também que acima de $2,5 \%$ de CPS ocorre melhora significativa na suculência, textura e apreciação geral do produto.

Pode-se observar pelas Figuras 3 e 4 que o CPS8002 apresentou o dobro de cinzas que o CPS80. Tal fato indica a presença de maior quantidade de sais, podendo explicar a diferença de comportamentos.

A adição de CPS80 aumentou os valores de umidade espremível, o que não é desejável para a salsicha por resultar em produto que perde água durante seu cozimento ficando ressecado.

As Figuras 7 e 8 evidenciaram maior valor de dureza para a formulação padrão, diferindo significativamente $(p<0,05)$ de 9 formulações. 


\section{FIGURA 7 - VALORES DE DUREZA PARAA FORMULAÇÃO PADRÃO E PARA AS FORMULAÇÕES COM 7\% DE CPS}

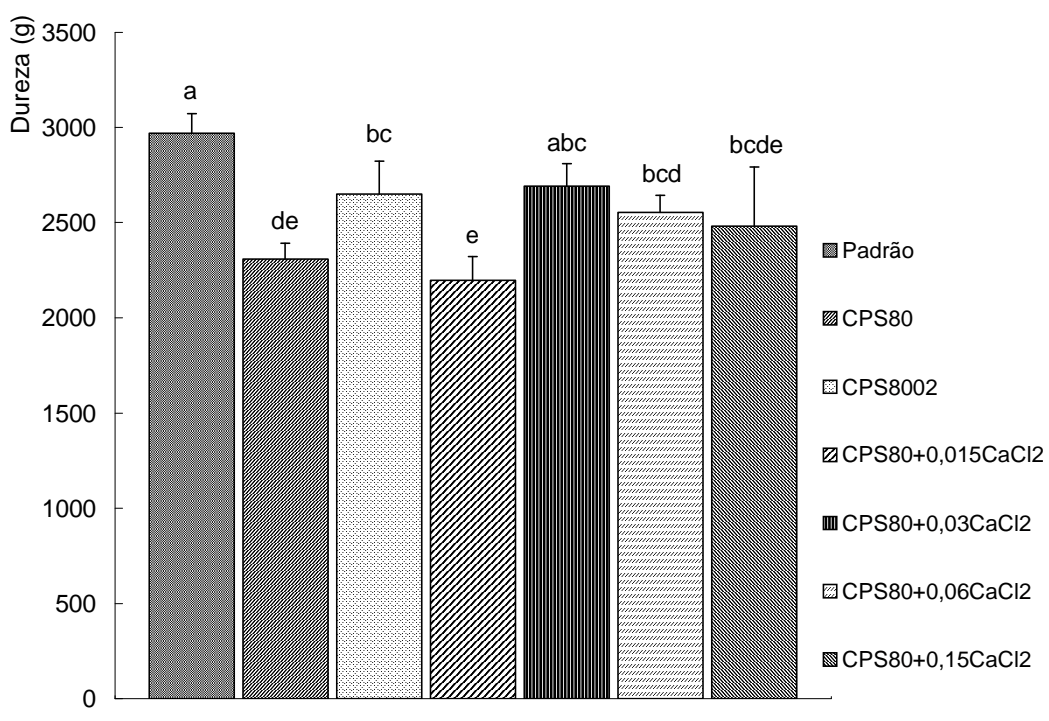

FIGURA 8 - VALORES DE DUREZA PARAA FORMULAÇÃO PADRÃO E PARA AS FORMULAÇÕES COM $8 \%$ DE CPS

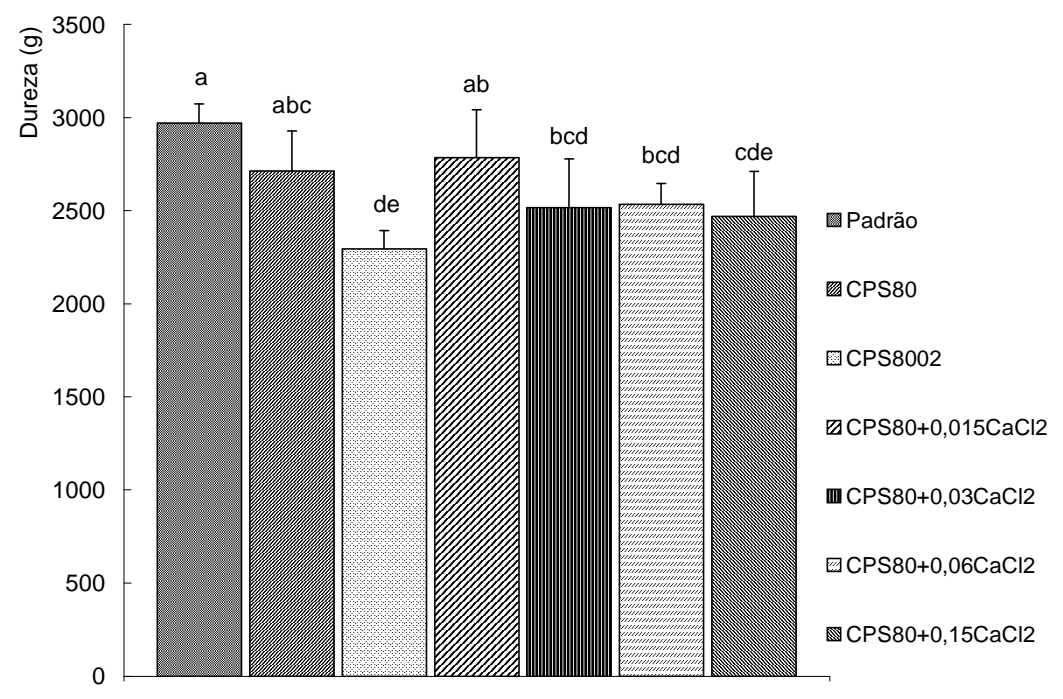


A elevação na concentração de proteínas do CPS80 aumentou o valor de dureza, ocorrendo o contrário com o CPS8002 (maior concentração de proteínas diminuiu o valor de dureza). A adição de $\mathrm{CaCl}_{2}$ também aumentou a dureza dos produtos.

MORR e FOEGEDING (1990) realizaram levantamento de várias propriedades químicas, físicas e funcionais dos produtos de soro de leite. Observaram que um dos CPS utilizados apresentou o mais alto nível de cálcio ( 3 vezes maior que o segundo maior valor) e magnésio (8 vezes maior que o segundo maior valor). O mesmo CPS exibiu a melhor propriedade gelatinizante dos produtos estudados, requerendo menor concentração protéica em todos os $\mathrm{pH}$ testados $(\mathrm{pH} \mathrm{4,5,} \mathrm{6,0} \mathrm{e}$ $7,5)$.

A adição de CPS80 e de $\mathrm{CaCl}_{2}$ não alterou significativamente os valores de elasticidade, quando comparado à formulação padrão (Figuras 9 e 10). A adição de CPS8002 aumentou o valor de elasticidade, apesar da diferença não ser significativa para as concentrações utilizadas $(p<0,05)$.

\section{FIGURA 9 - VALORES DE ELASTICIDADE PARA A FORMULAÇÃO PADRÃO E PARAAS FORMULAÇÕES COM 7\% DE CPS}

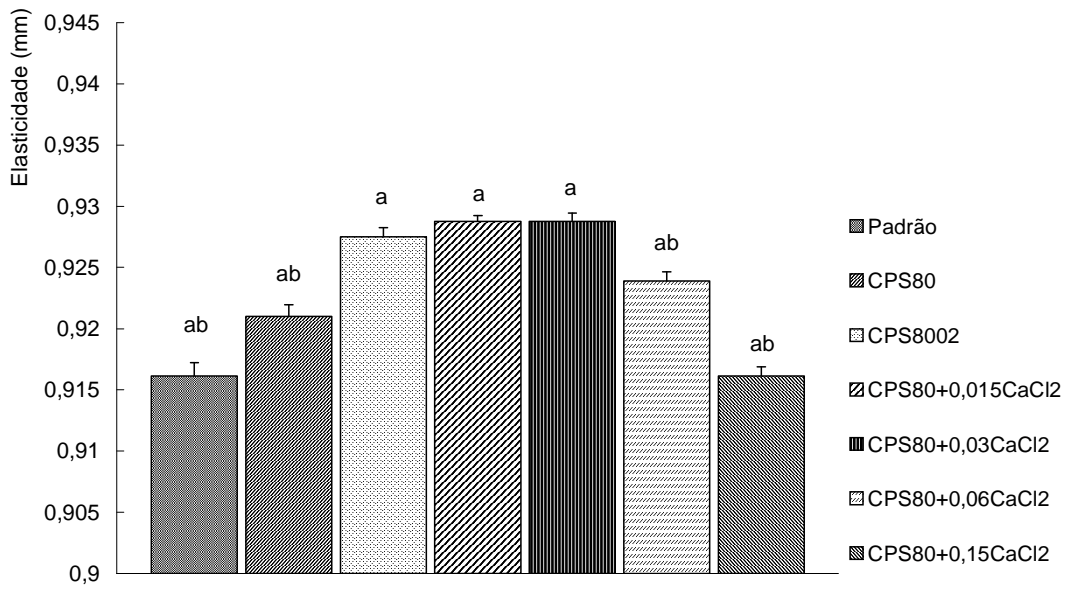




\section{FIGURA 10 - VALORES DE ELASTICIDADE PARA AS FORMULAÇÕES PADRÃO E AS FORMULAÇÕES TESTADAS COM $8 \%$ DE PROTEÍNA DO CPS}

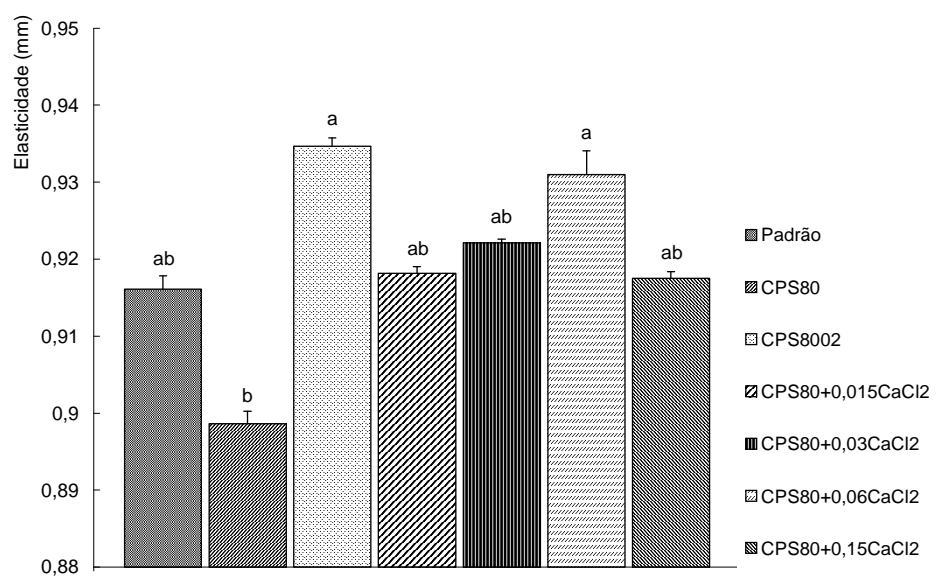

A substituição de proteína da carne por CPS80 ou CPS8002 com ou sem adição de $\mathrm{CaCl}_{2}$ causou diminuição no valor obtido para mastigabilidade em relação ao padrão (Figuras 11 e 12).

\section{FIGURA 11 - VALORES DE MASTIGABILIDADE PARA A FORMULAÇÃO PADRÃO E PARA AS}

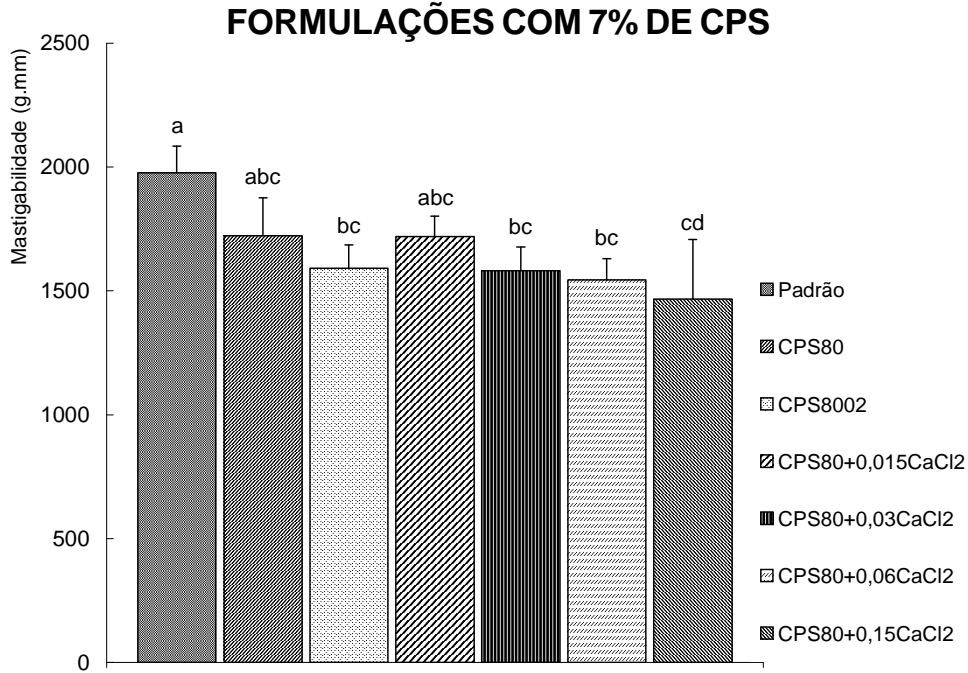




\section{FIGURA 12 - VALORES DE MASTIGABILIDADE PARA A FORMULAÇÃO PADRÃO E PARA AS FORMULAÇÕES COM $8 \%$ DE CPS}

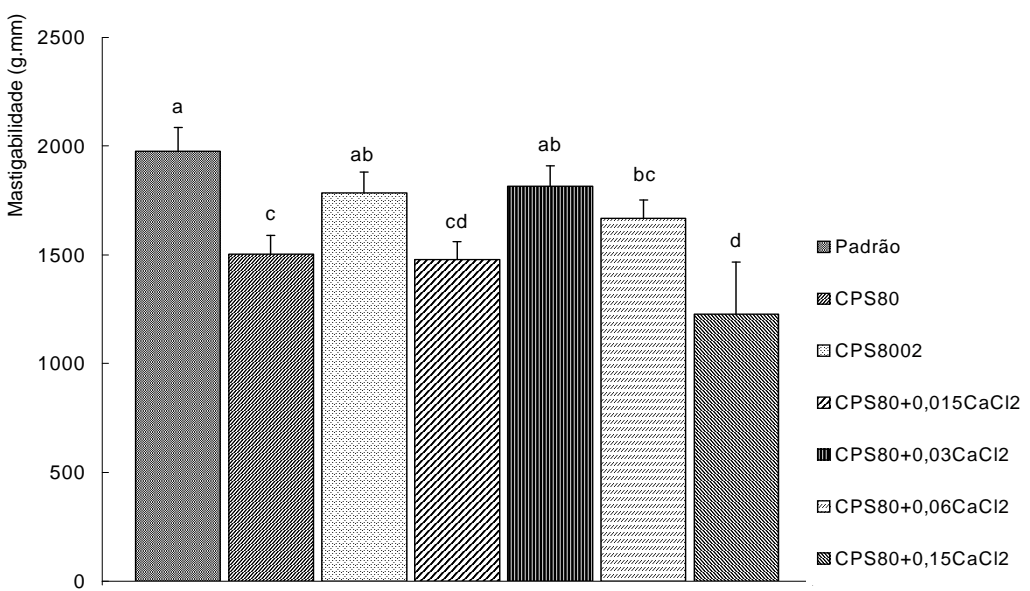

As adições de $\mathrm{CaCl}_{2}$ provocaram diminuição significativa (5\%) no valor de mastigabilidade comparado ao padrão, exceto para as formulações com $7 \%$ de CPS 80 e $0,03 \%$ de $\mathrm{CaCl}_{2}$ e $8 \%$ de proteínas do CPS 80 com $0,015 \%$ de $\mathrm{CaCl}_{2}$. Essas também apresentaram valores de mastigabilidade mais baixos que o padrão, mas não diferiram significativamente do padrão ao nível de 5\% (Figuras 11 e 12).

A adição de CPS80 e CPS8002 sem $\mathrm{CaCl}_{2}$ não alterou significativamente $(p<0,05)$ a coesividade. Mesmo não diferindo significativamente $(p>0,05)$ do padrão, as formulações com CPS 8002 (7 e $8 \%$ ) apresentaram valores maiores de coesividade do que o padrão (Figuras 13 e 14).

As formulações com $0,15 \%$ de $\mathrm{CaCl}_{2}$ mostraram valores de coesividade significativamente menores em relação ao padrão e às formulações sem adição de $\mathrm{CaCl}_{2}$. Verificou-se que a adição de altas concentrações de $\mathrm{CaCl}_{2}$ resultou em produtos mais quebradiços.

EL-MAGOLI, LAROIA e HANSEN (1996) mostraram que o $\mathrm{CaCl}_{2}$ exerce efeito negativo durante o cozimento, caracterizado pelo encolhimento do produto que também diminui o rendimento. 


\section{FIGURA 13 - VALORES DE COESIVIDADE PARA A FORMULAÇÃO PADRÃO E PARA AS FORMULAÇÕES COM 7\% DE CPS}

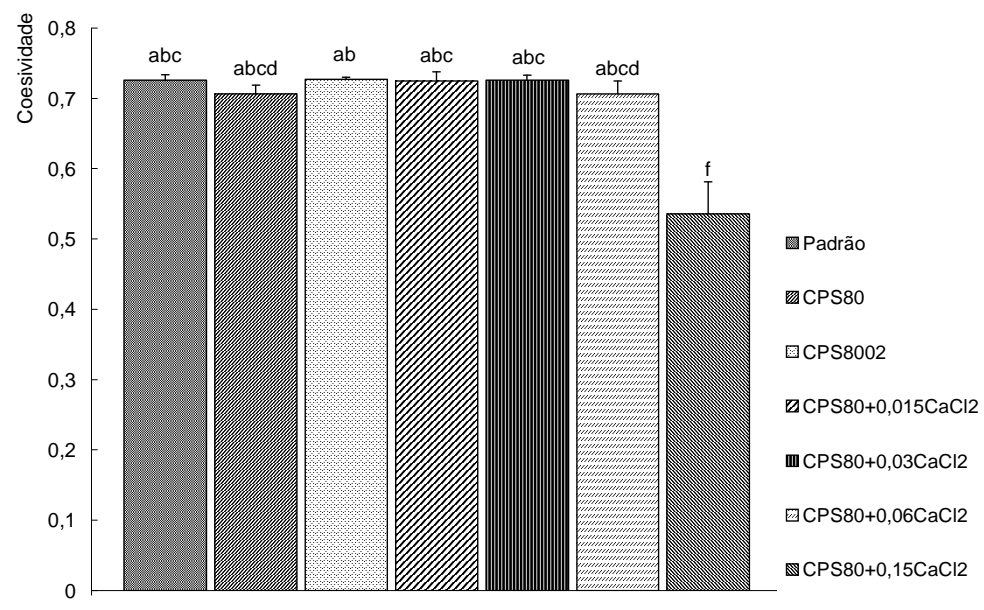

FIGURA 14 - VALORES DE COESIVIDADE PARA A FORMULAÇÃO PADRÃO E PARA AS FORMULAÇÕES COM 8\% DE CPS

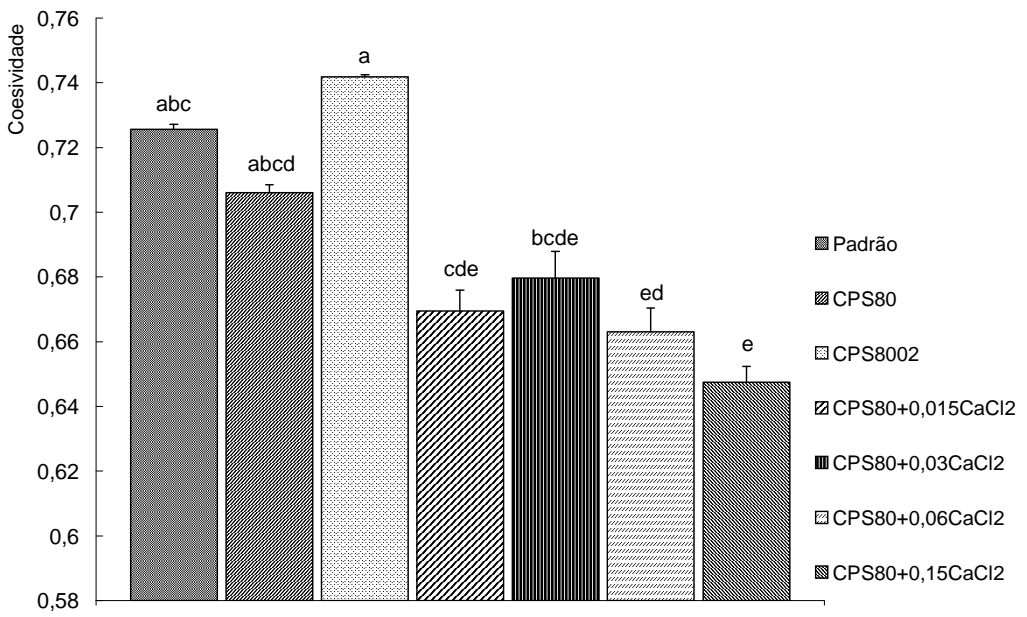


A adição de CPS80 com e sem $\mathrm{CaCl}_{2}$ não alterou significativamente o valor do parâmetro de cor L* em comparação com o padrão. Já a adição de CPS8002 aumentou o valor do parâmetro L*, tornando as amostras mais claras (Figuras 15 e 16).

\section{FIGURA 15 - VALORES DE COR L* PARA A FORMULAÇÃO PADRÃO E PARA AS FORMULAÇÕES TESTADAS}

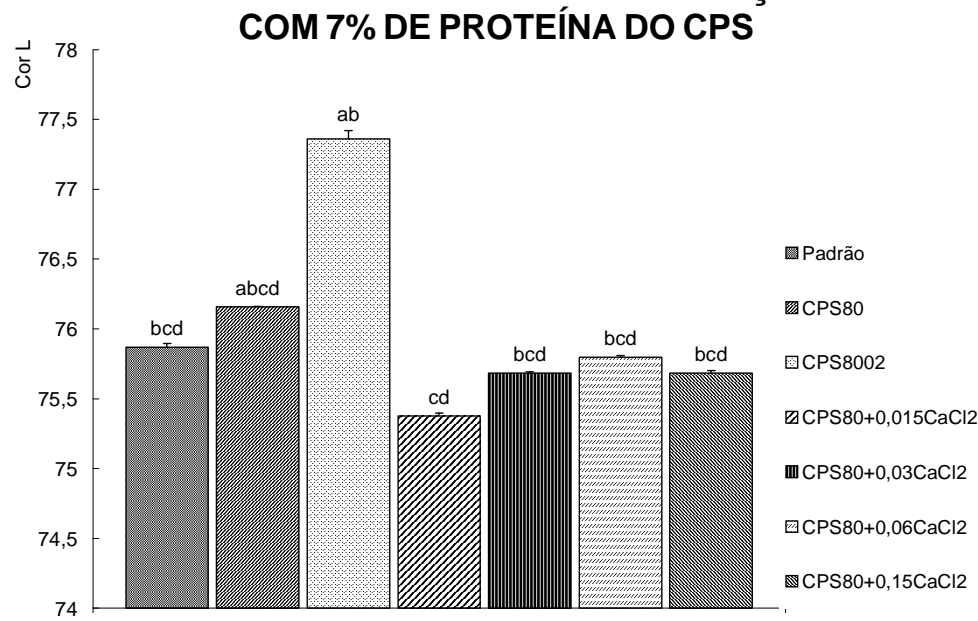
FIGURA 16 - VALORES DE COR L* PARA A FORMULAÇÃO PADRÃO E PARA AS FORMULAÇÕES TESTADAS COM 8\% DE PROTEÍNA DO CPS

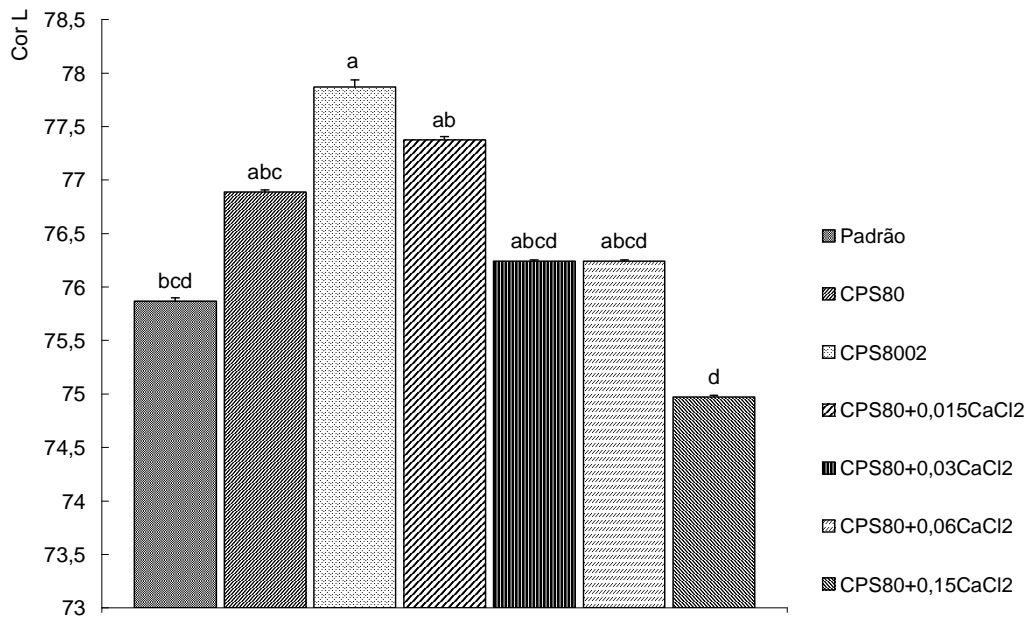




\section{FIGURA 17 - VALORES DE COR A* PARA A FORMULAÇÃO PADRÃO E PARA AS FORMULAÇÕES TESTADAS COM 7\% DE PROTEÍNA DO CPS}

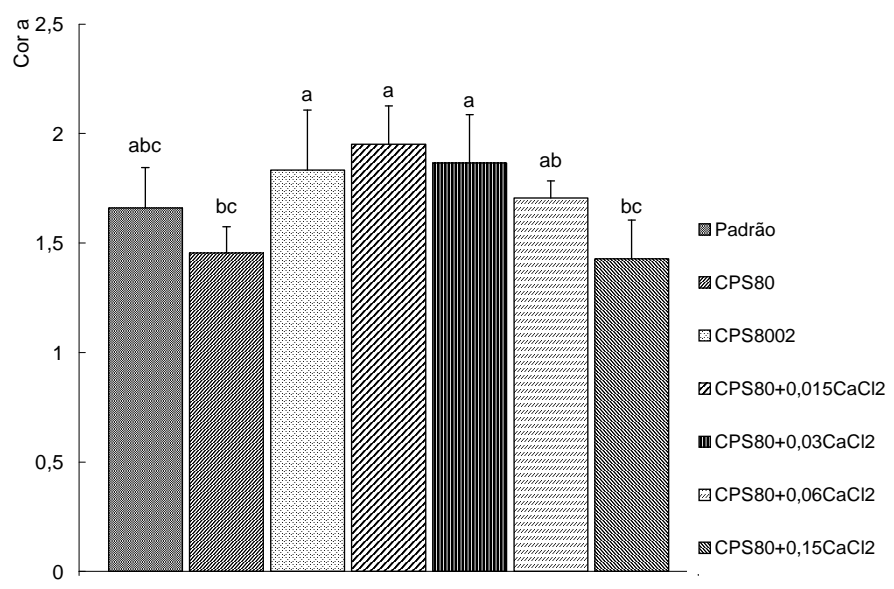

Os valores do parâmetro de cor a* mostraram-se bastante baixos, cujas variações não chegam a respresentar grandes mudanças de cor (Figuras 17 e 18).

\section{FIGURA 18 - VALORES DE COR A* PARA A FORMULAÇÃO PADRÃO E PARA AS FORMULAÇÕES TESTADAS COM $8 \%$ DE PROTEÍNA DO CPS}

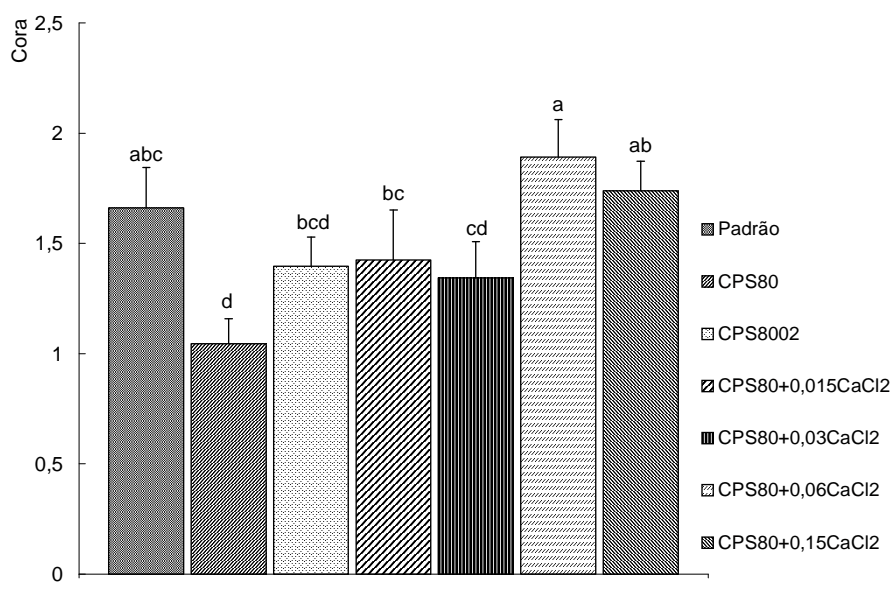


Na prática, conforme as Figuras 19 e 20, a adição de CPS80 e de CPS8002 não causou alteração significativa $(p<0,05)$ quanto ao parâmetro de cor $\mathrm{B}$.

\section{FIGURA 19 - VALORES DE COR B* PARA A FORMULAÇÃO PADRÃO E PARA AS FORMULAÇÕES COM 7\% DE CPS}

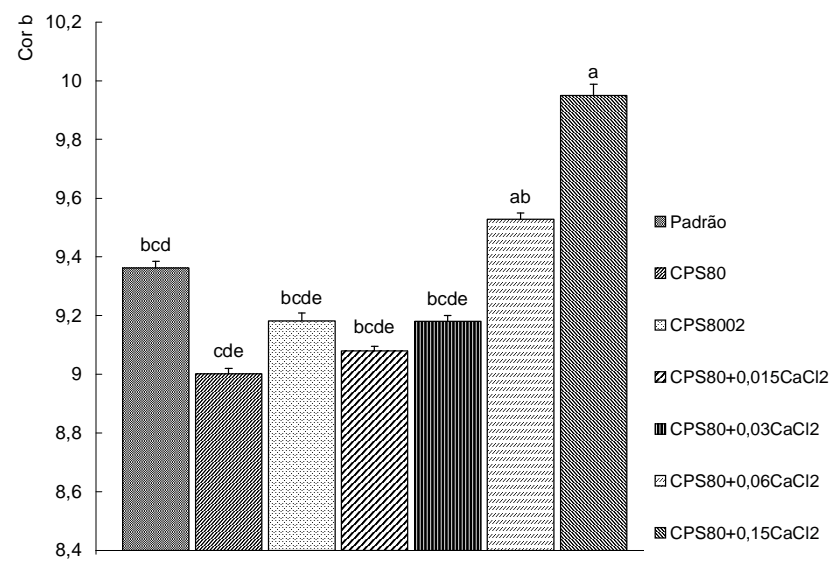

\section{FIGURA 20 - VALORES DE COR B* PARA A FORMULAÇÃO PADRÃO E PARA AS FORMULAÇÕES COM $8 \%$ DE CPS}

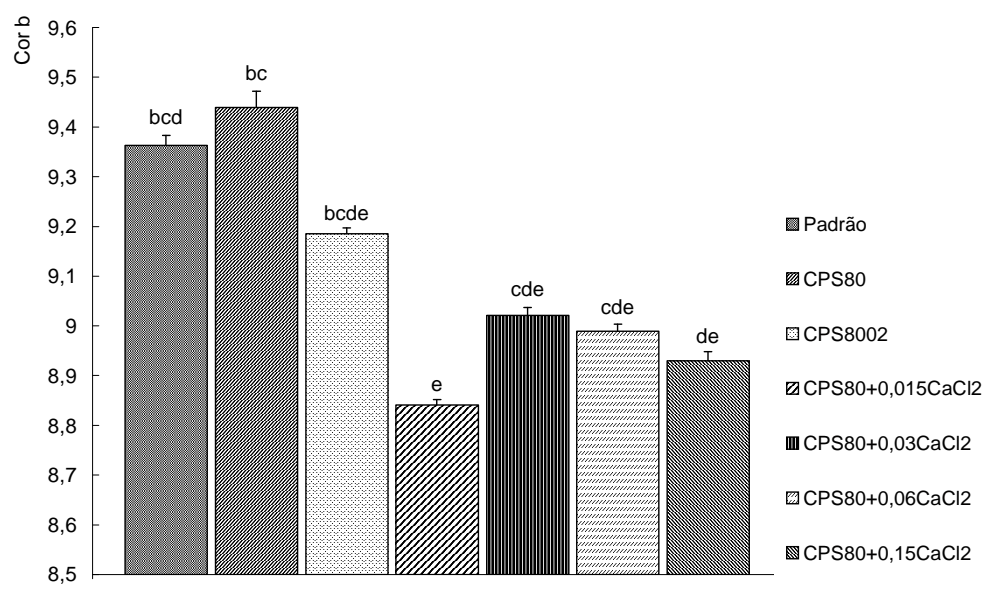




\title{
4 CONCLUSÃO
}

Concluiu-se que a substituição das proteínas cárneas por 7\% e 8\% de CPS alterou significativamente $(p<0,05)$ apenas a dureza e a mastigabilidade, respectivamente, resultando em produtos menos duros e mais fáceis de serem mastigados.

A substituição de 7\% e 8\% de proteínas cárneas por CPS8002 resultou em produtos com menor valor de dureza e maior luminosidade (na formulação com $8 \%$ de proteínas).

As adições de $\mathrm{CaCl}_{2}$, tanto na concentração de $7 \%$ como na concentração de $8 \%$ de CPS 80 , diminuíram significativamente $(\mathrm{p}<0,05)$ os valores de dureza e mastigabilidade. A adição de $0,15 \%$ de $\mathrm{CaCl}_{2}$ $(0,15 \%)$ diminuiu significativamente $(p<0,05)$ a coesividade das formulações. Conclui-se que não há necessidade da adição do $\mathrm{CaCl}_{2}$ para essas condições.

As análises físicas realizadas neste estudo mostraram que a substituição de proteínas da carne por CPS80 ou CPS8002 constitui alternativa viável para os "batters" cárneos, obtendo-se produtos com atributos de textura muito similares ao padrão. Para que essa afirmação tenha também respaldo sob o ponto de vista do consumidor sugere-se a realização de análise sensorial.

\begin{abstract}
THE EFFECT OF PROTEIN SUBSTITUTION OF THE MEAT FOR WHEY PROTEIN CONCENTRATES AND THE ADDITION OF $\mathrm{CaCL}_{2}$ IN A MEAT SYSTEM

The aim of this study was to evaluate the partial substitution of meat for CPS and to test the effect of $\mathrm{CaCl}_{2}$ addition in the system. The results have shown that the CPS 80 and CPS 8002 can be viable alternatives for meat "batters" giving rise to products with very similar attributes of texture as the control without any substitution. At the condition studied the addition of $\mathrm{CaCl}_{2}$ doesn't improve the rheological properties of the system.
\end{abstract}

KEY-WORDS: WHEY PROTEIN CONCENTRATES; SALTS; CALCIUM; SAUSAGE; MEAT SYSTEM. 


\section{REFERÊNCIAS}

1 AOAC. Association of Official Analytical Chemists. Official methods of analysis of AOAC international. $16^{\text {th }} \mathrm{ed}$. Washington, 1995.

2 CORREIA, L. R.; MITTAL, G. S. Functional properties of some meat emulsion extenders. International Journal of Food Properties, v. 3, n. 3, p. $353-361,2000$.

3 CONSENZA, G. H.; WILLIAMS, S. K.; JOHNSON, D.D.; SIMS, C.; McGOWAN, C. H. Development and evaluation of a cabrito smoked sausage product. Meat Science, v. 64, n. 2, p. 119-124, 2003.

4 DE WIT, J. N. The use whey protein product. In: FOX, P.F. (ed.) Development in Dairy Chemistry - 4. New York: Elsevier Applied Science, 1989. p. 323.

5 EL-MAGOLI, S. B.; LAROIA, S.; HANSEN, P. M. T. Flavor and texture characteristics of low fat ground beef patties formulated with whey protein concentrate. Meat Science, v. 42, n. 2, p. 179-193, 1996.

6 ENSOR, S. A.; MANDIGO, R. W.; CALKINS, C. R.; QUINT, L. N. Comparative evaluation of whey protein concentrate, soy protein isolate and calcium-reduced nonfat dry milk as binders in an emulsion-type sausage. Journal of Food Science, v. 52, n. 5, p. 1155-1158, 1987.

7 GORDON, A.; BARBUT, S. Mechanisms of meat batter stabilization: a review. Critical Reviews Food Science and Nutrition, v. 32, n. 4, p. 299-332, 1992.

8 HAMM, R. Biochemistry of meat hydration. Adv. Food Res., v. 10, p. 335 - 362., 1960.

9 JAUREGUI, C. A.; REGENSTEIN, J. M.; BAKER, R. C. A. Simple centrifugal method for measuring expressible moisture: a waterbinding property of muscle foods. Journal of Food Science, v. 46, p. 1271-1272, 1981.

10 LEE, A.; CANNON, R. Y.; HUFFMAN, D. L. Whey protein 
concentrates in a processed meat loaf. Journal of Food Science, v. 45 , p. $1278-1304,1980$.

11 KILARA, A. Whey protein functinality. In: HETTIARACHCHY, N.S.; ZIEGLER, G.R. (Ed.) Protein functionality in food systems. New York: Marcel Dekker, 1994. p. 325.

12 KUHN, P. R.; FOEGEDING, E. A. Mineral salt effects on whey protein gelation. Journal Agriculture Food Chemical, v. 39, n. 60, p. 1013, 1991.

13 MORR, C. V.; HA, E. Y. W. Whey protein concentrates and isolates: processing and functional properties. Critical Reviews Food Science and Nutrition, v. 33, n. 6, p. 431-436, 1993.

14 MORR, C. V.; FOEGEDING, E. A. Composition and functionality of commercial whey and milk protein concentrates and isolates: a status report. Food Technology, v. 44. n. 4, p. 100-112, Apr. 1990.

15 MULVIHILL, D. M.; KINSELLA J. E. Gelation characteristics of whey proteins and $\beta$-Lactoglobulin. Food Technology, v. 41, p. 102 111, 1987.

16 RAO, K. H.; ANJANEYULU, A. S. R.; SINGH, R. R. B.; DUBEY, P. C.; YADAV, P. L. Effect of whey protein concentrate on the quality of smoked chicken sausages from broiler spent hens. Indian Journal of Animal Sciences, v. 69, n. 6, p. 441-444, 1999.

17 SAS Institute. Statistical analysis system. Cary (USA), 1985.

18 SMITH, D. M. Meat Proteins: functional properties in comminuted meat products. Food Technology, v. 42, n. 4, p.116-121, 1988.

19 SMITH, D. M.; ROSE, A. J. Gel properties of whey protein concentrates as influenced by ionized calcium. Journal of Food Science, v. 59, n. 5, p. 1115-1118, 1994.

20 SMITH, D. M.; ROSE, A. J. Properties of chicken salt-soluble protein and whey protein concentrate gels as influenced by sodium tripolyphosphate. Poultry Science, v. 74, p. 169-175, 1995.

21 ZIEGLER, G. R.; ACTON, J. C. Mechanisms of gel formation by proteins of muscle tissue. Food Technology, v. 38, p. 77-83, 1984. 
22 WIERBICKI, E.; CAHILL, V. R.; DEATHERAGE, F. E. Effects of added sodium chloride, potassium chloride, calcium chloride, magnesium chloride, and citric acid on meat shrinkage at $70^{\circ} \mathrm{C}$ and of added sodium chloride on drip losses after freezing and thawing. Food Technology, v. 11, n. 2, p. 74-76, 1957. 